\title{
UMA LEITURA DE "ENFERMEIRINHAS ESPERTAS", CRÔNICA DE TEREZA QUADROS, MÁSCARA DE CLARICE LISPECTOR'
}

\author{
A READING OF "ENFERMEIRINHAS ESPERTAS" BY \\ TEREZA QUADROS, MASK OF CLARICE LISPECTOR
}

\author{
TÂNIA SANDRONI"
}

RESUMO: Este artigo apresenta uma leitura da crônica "Enfermeirinhas espertas", de Tereza Quadros (máscara de Clarice Lispector), publicada no semanário Comício, em 1952. A escritora era responsável pela coluna feminina "Entre mulheres" do veículo. Nessa página, a colunista publicou crônicas com incontestável valor literário, sendo que algumas delas deram origem a contos publicados posteriormente na obra lispectoriana. PALAVRAS-CHAVE: Clarice Lispector colunista, Tereza Quadros, Comício, jornalismo, literatura, crônica na década de 1950.

ABSTRACT: This article presents a reading of the literary chronicle "Clever Little Nurses" by Tereza Quadros (mask of Clarice Lispector), published in the weekly journal Comício in 1952. The writer was responsible for the journal's the feminine column "Among Women". On those pages, the columnist published literary chronicles of indisputable value, with a few of them originating short stories later published by the author.

KEYWORDS: columnist Clarice Lispector, Tereza Quadros, Comício, journalism, literature, literary chronicle in the 1950s.

10 artigo resultou da pesquisa de doutorado "A bela e a fera: a reafirmação do estereótipo feminino e sua subversão nas colunas de Tereza Quadros, máscara de Clarice Lispector", defendida em abril de 2018, sob orientação da Profa Dra Ivone Daré Rabello.

* Professora titular da Universidade Paulista e editora de comunicação no Colégio Santa Cruz. 


\section{Introdução}

Em 1952, no jornal Comício, Clarice Lispector produziu uma seção feminina sob a máscara de Tereza Quadros. O semanário, em formato tabloide, com 32 páginas, dirigido por Rubem Braga, Joel Silveira e Rafael Corrêa de Oliveira, contava com uma grande equipe de jornalistas e escritores, mas teve apenas 23 edições, devido a problemas financeiros. De acordo com Millôr Fernandes, um dos colaboradores, o veículo morreu de "leucemia administrativa" (in MESQUITA, 2008, p.203).

Clarice Lispector aceitou o convite de Rubem Braga e participou de 17 edições desse jornal, que ia na contramão da tendência da grande imprensa da época, permanecendo fiel ao estilo opinativo e aos modelos do jornalismo interpretativo, com grandes reportagens. Por ser um veículo relativamente à margem das exigências mercadológicas da produção jornalística, Comício conferia autonomia a seus colaboradores. Dessa forma, Clarice Lispector pôde elaborar a sua página até mesmo no aspecto visual. Ela selecionava as fotografias e as ilustrações e planejava o layout da coluna.

Na página, Tereza Quadros publicou 12 crônicas de sua autoria. Algumas delas deram origem a contos, posteriormente incorporados na obra clariciana. ${ }^{2}$ Neste artigo, apresentaremos uma leitura da crônica "Enfermeirinhas espertas", ${ }^{3}$ publicada em 31 de julho de 1952.

\section{A página "Entre mulheres" e a produção de Tereza Quadros}

A página "Entre mulheres", de Tereza Quadros, era composta por alguns textos, de diferentes tamanhos, fotos e ilustrações. As fotografias referiam-se essencialmente a questões de moda e ocupavam parte considerável da coluna. A imagem a seguir ilustra a sua composição.

2 A crônica "Um dia cheio" deu origem ao conto "Uma tarde plena" e a crônica "Pastoral" transformou-se no conto "A repartição dos pães".

3 De acordo com nossa pesquisa, essa crônica não se encontra analisada em nenhuma publicação. 


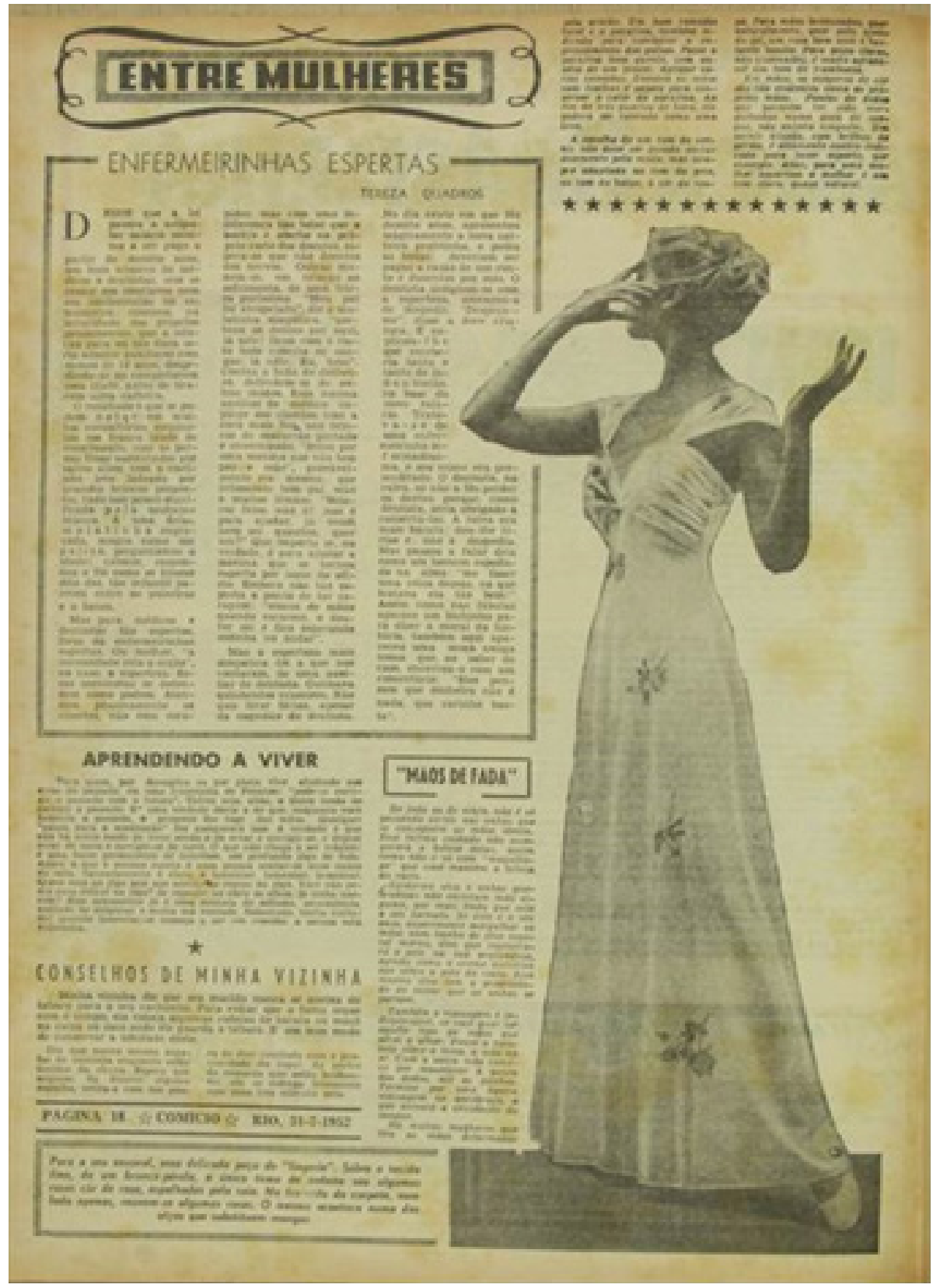

Figura 1: Imagem da 11a edição da página "Entre mulheres". Comício, 31 jul. 1952. 
Em todas as edições, havia um ou dois textos principais, que invariavelmente apresentavam um discurso anticonvencional em relação ao hegemônico da imprensa feminina da época. Na imagem, percebe-se que, nessa edição, a crônica "Enfermeirinhas espertas" foi destacada em um box. Tereza Quadros também planejou algumas seções fixas dentro da página, como "Aprendendo a viver" e "Conselhos da minha vizinha", presentes em várias edições.

Em "Conselhos de minha vizinha", a autoridade da fala para solucionar os diversos problemas cotidianos parte de uma vizinha anônima, que remete a uma figura comum do universo feminino provinciano, em que é comum a conversa com as vizinhas em busca de conselhos diversos.

A vizinha, que sabe de tudo, opõe-se aos saberes institucionalizados de especialistas, e sua voz, na página, ganha a autoridade da sabedoria popular, fundada na experiência. O conteúdo da seção é convencional, direcionado às tarefas domésticas, mas a abordagem é original. Em uma época em que o discurso científico se impunha como conhecimento hegemônico, a figura da vizinha se contrapunha a ele, validando práticas e costumes das antigas gerações.

O texto a seguir, publicado em 30 de maio de 1952, mostra o estilo da seção, composta por fragmentos com pequenos conselhos e receitas para as tarefas cotidianas.

\section{Conselhos de minha vizinha}

Para acalmar enxaquecas, minha vizinha derrama algumas gotas de limão na xícara de café bem quente, antes de tomá-lo.

Preparando qualquer massa - seja torta, seja para bolos e pastéis - ela amorna um pouco o leite ou a água ou qualquer outro líquido que entre na sua composição. Assim, consegue que a massa cresça mais depressa e se torne mais leve.

$* * *$

Diz que maçã combate insônia.

\section{$* * *$}

Ela passa óleo nas solas dos sapatos das crianças, repetindo a operação até que o couro absorva a gordura. Esse processo impermeabiliza o sapato. 
Quando ela quer que o assado dê bom molho e mais caldo, acrescenta-lhe um pouco de açúcar. A carne não fica doce, porém verte mais sumo. (LISPECTOR, 1952a)

A atuação da colunista era ambivalente. Ao mesmo tempo em que vários conselhos, dicas e receitas procuravam adaptar a mulher ao universo doméstico postura bastante comum na imprensa feminina -, havia outros textos que questionavam esse modelo e defendiam a emancipação feminina, especialmente por meio do trabalho. Essa era uma questão bastante mencionada na página "Entre mulheres": a importância de a mulher trabalhar não só para ter meios próprios de subsistência, mas também como forma de realização pessoal.

Isso pode ser observado na citação que a colunista faz de um trecho do livro O segundo sexo, de Simone de Beauvoir, ${ }^{4}$ lançado na França, com bastante polêmica, apenas três anos antes.

Como se vê no texto a seguir, a colunista simplesmente colocou entre aspas o trecho da escritora francesa, com a indicação de fonte:

"Estou convencida de que a grande maioria dos mal-estares e doenças que atingem as mulheres tem causas psíquicas. É por causa da tensão moral de que eu falei, por causa de todas as tarefas que assumem, das contradições do ambiente no qual se debatem, que as mulheres estão constantemente cansadas, até o limite das forças. Isso não significa que seus males sejam imaginários: eles são reais e devorantes como a situação que exprimem. Mas a situação não depende do corpo, é este que depende dela. Assim, a saúde não prejudicará o trabalho da mulher quando esta tiver na sociedade o lugar de que ela precisa. Pelo contrário, o trabalho a ajudará poderosamente a obter um equilíbrio físico, não lhe permitindo que se preocupe com este sem cessar." (Le Deuxième Sexe, Simone de Beauvoir). (LISPECTOR, 1952b)

Reforçando a atuação não convencional em uma página feminina, Clarice Lispector produziu, com regularidade, crônicas dotadas de literaturidade, tal como a definiram os chamados formalistas russos. Em outras palavras, algumas crôni-

4 Na nossa pesquisa, constatamos que a colunista publicou trechos de outros autores citados por Simone de Beauvoir, dando apenas a referência original de autoria. 
cas de Tereza Quadros apresentam características consideradas literárias, como a desautomatização da linguagem, a multissignificação, o predomínio da conotação, a liberdade na criação temática, a ênfase no significante e a variabilidade.

Por meio de um modo especial de elaboração, por uma organização de linguagem que a afasta das ocorrências mais ordinárias dos arranjos verbais e pela combinação de fatos lexicais, semânticos, fônicos e sintáticos, a cronista produziu textos diferenciados em relação aos que a imprensa feminina costumava publicar (normalmente histórias moralizantes e adocicadas). Essa diferenciação é notada não só na abordagem temática, mas também na estruturação formal.

Na avaliação do valor literário dos textos, não podem ser esquecidas as peculiaridades da crônica, considerada como um gênero híbrido entre o jornalismo e a literatura e, por isso, com a transitoriedade e a leveza da imprensa e sem a grandeza temática e estilística de outros textos literários. Se, por um lado, a crônica é considerada estilisticamente menos elaborada do que o conto ou do que o romance, por outro, a percepção "ao rés do chão", como apontou Antonio Candido, torna-a mais próxima do leitor e permite que ela revele fatos cotidianos por ângulos pouco usuais.

Segundo Arrigucci (1987, p. 53):

Não raro ela [a crônica] adquire [...], entre nós, a espessura do texto literário, tornando-se, pela elaboração da linguagem, pela complexidade interna, pela penetração psicológica e social, pela força poética e pelo humor, uma forma de conhecimento dos meandros sutis de nossa realidade e de nossa história.

Embora Clarice Lispector só tenha assumido a escrita de crônicas quando ocupou essa função no Jornal do Brasil, em Comício, ela já as realizava. Até o final da década de 1960, ela afirmava não saber como produzir algo do gênero. No texto publicado em 22 de junho de 1968 no Jornal do Brasil, escreveu:

Crônica é um relato? é uma conversa? é o resumo de um estado de espírito? Não sei, pois antes de começar a escrever para o Jornal do Brasil, eu só tinha escrito romances e contos. Quando combinei com o jornal escrever aqui aos sábados, logo em seguida morri de medo. (LISPECTOR, 1999, p. 67) 
Assim, mesmo negando o domínio desse gênero até os anos 1960, ela produziu, com a máscara de Tereza Quadros, crônicas que proporcionam à leitora um olhar diferenciado sobre aspectos da nossa sociedade e revelam a importância de se prestar atenção ao cotidiano e de desautomatizar a percepção a respeito daquilo que nos cerca.

Em alguns textos, é possível identificar traços da obra literária de Clarice Lispector. Por isso, pode-se dizer que o exercício de colunista feminina em Comício parece ter influenciado a obra da escritora em alguns aspectos.

Em primeiro lugar, na inspiração e na transfiguração de temas ao se apropriar realística e criativamente do cotidiano da mulher urbana de classe média. Além de aproximar a escritora do imaginário da mulher burguesa, a atividade de colunista auxiliou no aperfeiçoamento de narrativas mais curtas e mais simples e afastou-a da fama de escritora hermética, que a acompanhou desde o lançamento de seus primeiros romances, fato só nuançado quando a produção de contos, depois reunidos em livros, ampliou o público leitor de suas obras. Claro que não se pretende sugerir que, na época de Tereza Quadros, a escritora já não dominasse a técnica do conto ou que não abordasse o universo da identidade feminina e seu papel social na sua obra. O que se pode afirmar é que as colunas, como prática de escrita, potencializaram e amadureceram essas qualidades e influenciaram a produção ficcional da escritora.

Três dos textos produzidos em "Entre mulheres" posteriormente se transformaram em contos e, em algumas crônicas, podem ser apreendidos aspectos estilísticos e temáticos da obra literária de Clarice Lispector. $\mathrm{O}$ fenômeno do reaproveitamento de textos ou trechos e esse fluxo entre jornalismo e literatura são comuns na obra clariciana. De acordo com Vilma Arêas (2005, p.36),

crônicas e romances, livros ou capítulos funcionam como vasos comunicantes. Os textos do jornal seguem para o livro e vice-versa, repetidos nos livros, repetidos no jornal, às vezes até aspeados como se fossem citações de outro autor e não da própria Clarice. Dividida entre o jornal e a literatura, Clarice Lispector muitas vezes não separou por completo as duas atividades. Como se Clarice diagramasse a si própria, mudando de roupa (de forma) segundo a ocasião. 
Ainda segundo a crítica, Clarice Lispector produzia, para o jornal, textos mais diretos e, para o livro, textos com mais recursos e artifícios, "o que muitas vezes conta mais pontos para as crônicas, em termos de funcionalidade" (ibid., p. 36).

\section{As enfermeirinhas e o quadro das relações trabalhistas no início da década de 1950}

Apresenta-se, a seguir, uma leitura da crônica "Enfermeirinhas espertas", publicada na 11a edição de Comício.

\section{Enfermeirinhas espertas \\ Tereza Quadros}

Desde que a lei passou a estipular salário mínimo a ser pago a partir de dezoito anos, um bom número de médicos e dentistas, sem se reunir em conclaves nem em conferências no estrangeiro, resolveu, na intimidade dos próprios pensamentos, que a solução para lei tão dura seria admitir auxiliares com menos de 18 anos, despedindo-as ao completarem essa idade, antes de tirarem nova carteira.

0 resultado é que se podem notar em muitos consultórios meninotas em franca idade de crescimento, com as pernas finas sustentadas por saltos altos, com o rostinho leve ladeado por grandes brincos pingentes, tudo isso pouco dignificado pelo uniforme branco. A uma delas, mulatinha engraçada, magra como um palito, perguntamos a idade: catorze, respondeu e foi como se tivesse dito dez, tão infantil pareceu entre as pulseiras e o batom.

Mas para médicos e dentistas tão espertos, Deus dá enfermeirinhas espertas. Ou melhor, "a necessidade cria o órgão", no caso a esperteza. Essas meninotas se defendem como podem. Atendem pessimamente os clientes, não com estupidez, mas com uma indiferença tão total que o bocejo é aberto no próprio rosto dos doentes, espera-se que não doentes dos nervos. Outras munem-se, em relação ao sofrimento, de uma frieza puríssima. "Meu pai foi atropelado", diz a mulatinha simpática, "quebrou os dentes por aqui, lá nele! ficou com o rosto todo coberto de sangue, lá nele. Eu, hem". Contra a falta de dinheiro, defendem-se de outros modos. Essa mesma auxiliar de médico impinge aos clientes, com a cara mais lisa, uns brincos de macarrão pintado e envernizado, "feitos por uma menina que não 
tem nem pai nem mãe", provavelmente ela mesma, que felizmente tem pai, mãe e muitos irmãos. "Brincos feios, não é? Mas é para ajudar, já vendi nem sei quantos, quer um?" Que importa se, na verdade, é para ajudar a menina que se tornou esperta por ossos do ofício. Embora não tão esperta a ponto de ter coragem: "morro de medo quando escurece, o doutor sai e fico esperando sozinha no andar". Mas a esperteza mais simpática foi a que nos contaram, de uma auxiliar de dentista. Ganhava quinhentos cruzeiros. ${ }^{5}$ Não quis tirar férias, apesar da sugestão do dentista. No dia exato em que fez dezoito anos, apresentou magicamente a nova carteira prontinha e pediu as férias: deveriam ser pagas a razão de um conto e duzentos por mês. O dentista indignou-se com a esperteza, ameaçou-a de despedir. "Despeça-me", disse a doce criatura. E explicou-Ihe que receberia tanto e tanto de indenização, na base do novo salário. Tratava-se de uma enfermeirinha informadíssima, e seu crime era premeditado. O dentista, na raiva, só não a fez perder os dentes porque, como dentista, seria obrigado a consertá-los. A raiva era mais barata: deu-lhe férias e não a despediu. Mas passou a falar dela como um homem espoliado na alma: "me fazer uma coisa dessas, eu que tratava ela tão bem!". Assim como nas fábulas aparece um bichinho para dizer a moral da história, também aqui apareceu uma moça amiga nossa que, ao saber do caso, encerrou-o com um comentário: "Eles pensam que dinheiro não é nada, que carinho basta". (LISPECTOR, 1952c)

Como se vê, em um texto leve, com sintaxe simples e vocabulário acessível, como convém à crônica moderna, Tereza Quadros aborda, em tom de conversa entre amigas, de forma aparentemente despretensiosa, relações trabalhistas e sociais no início da década de 1950 a partir de um caso específico: a manobra de médicos e dentistas para não pagarem, como mandava a "lei tão dura", o salário mínimo a suas atendentes.

Já no primeiro parágrafo percebe-se ironia com relação às atitudes do patronato, que tem a infração como norma introjetada, "na intimidade dos próprios pensamentos", e que não precisa de "conclaves e conferências" para garantir seus interesses. Mesmo sem combinações formalizadas, a prática de burlar a lei é comum e existe cumplicidade de classe para fazê-lo e levar vantagem.

5 O valor pago correspondia a cerca de $40 \%$ do salário mínimo da época. 
A crítica da crônica é voltada à permanência de relações trabalhistas arcaicas em um período marcado pelo desejo de modernização. De forma "oblíqua e dissimulada", 6 a cronista revela aspectos e reflexos do conflito de interesses de classes em um cenário em que as leis trabalhistas vigoravam há alguns anos. É bom lembrar que o salário mínimo foi oficializado por um decreto de Vargas em 1ㅇ de maio de 1940 e a CLT entrou em vigor em 1943.

Nesse contexto, a crônica revela o antagonismo entre os princípios da impessoalidade, que deveriam reger as relações de trabalho recém-determinadas por lei e que são marca da sociedade moderna e industrial, e a manutenção dos vínculos da pessoalidade, historicamente enraizados na formação da sociedade brasileira devido às sólidas bases da família rural e patriarcal, como assinalou Sérgio Buarque de Holanda. De acordo com o historiador, nossas formas de convívio, marcadas pela cordialidade, são comumente ditadas por uma "ética de fundo emotivo", e "permanece ativa e fecunda a influência ancestral dos padrões de convívio humano, informados no meio rural e patriarcal. Seria engano supor que essas virtudes possam significar 'boas maneiras', civilidade. São antes de tudo expressões legítimas de um fundo emotivo" (HOLANDA, 2006, p.160).

Na crônica, o vínculo empregador/empregado, entre doutores e enfermeirinhas, sustenta-se por uma relação pouco impessoal, em um regime de trabalho que desrespeita a regulamentação por um ardil - empregar meninotas de menos de 18 anos -, apesar das exigências que impunha o novo quadro de ímpeto modernizante da época. O aspecto pessoal continua permeando a relação empregado-empregador e organizando as relações de trabalho, decerto para vantagem apenas do detentor do capital (no caso, o profissional liberal). Além do personalismo, observam-se, no fato narrado, aspectos do paternalismo, apreendidos nas relações familiares, que faz do afeto pressuposto um componente das relações de opressão ${ }^{7}$. Ainda de acordo com Sérgio Buarque de Holanda (ibid.,

\footnotetext{
6 Expressão de Davi Arrigucci no texto "Fragmentos sobre a crônica" (1987, p. 61). Embora ele a utilize para um contexto diferente da crônica de Tereza Quadros, julgamos que cabe também neste caso.

7 Cabe lembrar que quem melhor deu formalização à violência das relações paternalistas foi Machado de Assis. Podemos citar, por exemplo, o episódio em que o protagonista, protegido pelo pai abastado, fazia maldades com o escravo Prudêncio e com a cozinheira, no capítulo "O menino é pai do homem", do livro Memórias póstumas de Brás Cubas. O que poderia ser feito no âmbito privado, com louvor do pai, é censurado quando exercido em público.
} 
p.160), "as relações que se criam na vida doméstica sempre forneceram o modelo obrigatório de qualquer composição social entre nós".

A cordialidade, no entanto, não deve ser confundida apenas com afeto genuíno e positivo. O familismo apresenta seu lado perverso, em que se acentuam a dependência e a falta de garantias do polo mais fraco. Nesse ambiente íntimo, abrem-se caminhos para a exploração, que não mostra claramente sua face, sendo mascarada por um verniz de "carinho".

Nesse cenário, a atitude da enfermeirinha informadíssima, ao exigir seus direitos trabalhistas, também ela por meio de um ardil, configura-se para o doutor como uma ofensa pessoal e uma traição, o que se reflete na reação de decepção e de raiva do dentista, que "a tratava tão bem". A raiva levaria à violência que, nesses tempos, porém, custaria caro. Em nome do dinheiro, ele prefere seguir a lei, mas sente-se como um "homem espoliado na alma".

$\mathrm{O}$ fato de o doutor oferecer oportunidade de emprego a mocinhas pobres, mulatinhas, aparece caracterizado, no discurso patronal, como um favor, uma concessão que já deveria garantir a gratidão eterna das auxiliares.

Por isso, a reação final da enfermeirinha que se antepõe com os direitos - em uma postura de enfrentamento ("despeça-me") - causa espanto no patrão. E a sua esperteza é marcada pela agilidade na ação (no dia em que completou 18 anos já levou a nova carteira "magicamente") e pelo conhecimento (a menina era bem informada sobre seus direitos), o que comprova a consciência de um trabalhador, que, para o patrão, era premeditação e "crime".

A crônica revela, de fato, uma disputa entre "espertezas", em condições bem desiguais. A esperteza dos patrões é revidada com a esperteza das enfermeirinhas: "para médicos e dentistas tão espertos, Deus dá enfermeirinhas espertas. Ou melhor, 'a necessidade cria o órgão', no caso, a esperteza. Essas meninotas se defendem como podem". Para garantir seus direitos, as enfermeirinhas recorreriam à esperteza, a subterfúgios necessários para driblar a exploração. Contra o poder, antepõe-se a esperteza.

Um desses mecanismos é a forma de aumentar a pouca renda que recebem dos patrões, vendendo bugigangas. A manobra não escapa à cronista, que descreve a enfermeirinha "com a cara mais lisa", tentando impor a compra de "uns brincos de macarrão pintado e envernizado", presumivelmente feitos "por ela mesma", "que felizmente tem pai, mãe e muitos irmãos", mas que ela anuncia como produtos de uma jovem órfã. Mesmo denunciando a malandragem da 
menina, a cronista parece aderir a ela, considerando suas necessidades e fragilidades, e afirma que pouco importa se a história contada para comover as clientes é verdadeira ou não.

Estrategicamente, a colunista constrói uma narradora na primeira pessoa do plural e atribui a vozes anônimas fatos narrados ("nos contaram", "uma amiga nossa" comentou), o que retira a exposição mais direta da subjetividade da cronista. Isso, entretanto, não apaga o ponto de vista de quem narra. Aparentemente, a voz da cronista se posiciona junto com as pacientes de médicos e dentistas, que são incomodadas pelo mau atendimento das mocinhas. No entanto, a cronista, em vez de se irritar com essa postura (que supostamente seria a reação mais comum das pacientes), mostra simpatia pelas atitudes espertas das enfermeirinhas ("a esperteza mais simpática foi a que nos contaram, de uma auxiliar de dentista"). Ela entende como justo o revide -- que se revela, de fato, como luta por direitos já conquistados pela classe trabalhadora e que é entendido pelos patrões como ingratidão. A narradora ironiza o discurso do patronato, segundo o qual, os trabalhadores não sabem valorizar as oportunidades e os benefícios que recebem e são ingratos em relações aos seus patrões, que lhes provêm o sustento. Como se, na ótica desse patronato, empregar menores de idade não fosse desrespeito, e sim favor.

Nesse conflito, o diminutivo em "enfermeirinhas", ao mesmo tempo em que revela a pouca idade das auxiliares, também atribui um sentido de desvalorização profissional. São "enfermeirinhas", não são profissionais bem formadas, como médicos e dentistas, doutores e sujeitos do saber, agentes sociais importantes no quadro modernizador do Brasil. Assim, só Ihes restaria a esperteza como forma de defesa e de luta.

No texto, as meninas, mesmo sem formação escolar completa, exerciam a função de enfermeiras, o que também pode explicar, em parte, o mau atendimento aos clientes. A mão de obra não formada, não especializada, e, por isso mesmo, mais barata, era atraente para os patrões, que, assim, não eram obrigados a pagar o salário mínimo a suas atendentes.

O final do texto parodia a estrutura de uma fábula e apresenta a moral da história na voz do comentário de uma suposta amiga, que resume o caso com a oposição entre carinho e dinheiro, atacando as relações afetivas que, no paternalismo, tudo justificariam. 
Tal tema ser abordado em uma coluna feminina parece, à primeira vista, ser justificado pelo fato de as leitoras frequentarem clínicas de médicos e dentistas e terem que lidar com o mau atendimento das "enfermeirinhas espertas" ou terem que se desviar da venda de quinquilharias. No entanto, a leitura atenta revela que a importância do tema encontra-se na denúncia de relações trabaIhistas, com exploração da mão de obra, abordando a participação de mulheres de classes subalternas no mercado como coadjuvantes - exploradas como mão de obra sem direitos estabelecidos, também por serem menores de idade -- de profissionais socialmente reconhecidos. As armas dos explorados surgem não apenas da "malandragem" (como na venda de bijuterias), mas também do conhecimento dos direitos.

\section{Considerações finais}

Clarice Lispector atuou como colunista feminina por três vezes. Em todas as ocasiões, as suas produções não foram assinadas com seu nome. Em 1952, ela foi Tereza Quadros, em Comício; de 1959 a 1961, foi Helen Palmer, no Correio da Manhã; e, de 1960 a 1961, foi ghostwriter da atriz Ilka Soares, no Correio da Noite.

A leitura dessa produção de Clarice Lispector permite perceber que a atuação de Tereza Quadros é a mais autoral e a que assume uma postura contra-hegemônica em relação ao discurso da imprensa feminina. Tereza Quadros reproduziu trechos de outros autores que devem ter levado a leitora a questionar sobre os modelos comportamentais destinados às mulheres na sociedade patriarcal e criou crônicas que contribuíram para ampliar o olhar da leitora em relação ao cotidiano e à estrutura social.

A crônica "Enfermeirinhas espertas", aqui apresentada, ilustra a atuação da colunista e revela o rosto da Clarice Lispector escritora, visível sob a máscara de Tereza Quadros. 


\section{Referências}

ARÊAS, Vilma. Clarice Lispector com a ponta dos dedos. São Paulo: Companhia das Letras, 2005. ARRIGUCCI JR., Davi. Enigma e comentário. São Paulo: Companhia das Letras, 1987. BEAUVOIR, Simone de. O segundo sexo. Rio de Janeiro: Difusão Europeia do Livro, 1967. BUITONI, Dulcília Schroeder. A imprensa feminina. São Paulo: Ática, 1986.

BUITONI, Dulcilia Schroeder. Mulher de papel: a representação da mulher na imprensa feminina brasileira. São Paulo: Edições Loyola, 2009.

CANDIDO, Antonio et al. A crônica: o gênero, sua fixação e suas transformações no Brasil. Campinas: Unicamp, 1992.

CARVALHO, Marco Antonio de. Rubem Braga: um cigano fazendeiro do ar. São Paulo: Biblioteca Azul, 2013.

GASPAR, Samantha dos Santos. Rubem Braga e o semanário Comício. Dissertação (Mestrado em Antropologia) - Universidade de São Paulo. São Paulo, 2012.

HELENA, Lúcia. Nem musa nem medusa: itinerários da escrita em Clarice Lispector. Rio de Janeiro: EDUFF, 1997.

HOLANDA, Sérgio Buarque de. Raízes do Brasil. Edição comemorativa dos 70 anos. São Paulo: Companhia das Letras, 2006.

GOTLIB, Nádia Battella. Clarice: uma vida que se conta. São Paulo: Edusp, 7 ed., 2013.

LISPECTOR, Clarice. Correio feminino. Org. de Aparecida Maria Nunes. Rio de Janeiro: Rocco, 2006a.

LISPECTOR, Clarice. Só para mulheres. Org. de Aparecida Maria Nunes. Rio de Janeiro: Rocco, 2006b.

LISPECTOR, Clarice. Outros escritos. Org. de Teresa Montero e Lícia Manzo. Rio de Janeiro: Rocco, 2006c.

LISPECTOR, Clarice. A descoberta do mundo. Rio de Janeiro: Rocco, 1999.

LISPECTOR, Clarice. Entre mulheres. Comício, 30 maio 1952a. Disponível em: <http://docvirt.com/ DocReader.net/DocReader.aspx?bib=AcervoRubemBraga>. Acesso em: 18 dez. 2018.

LISPECTOR, Clarice. Entre mulheres. Comício, 11 jul. 1952b. Disponível em: <http://docvirt.com/DocReader.net/DocReader.aspx?bib=AcervoRubemBraga>. Acesso em: 18 dez. 2018.

LISPECTOR, Clarice. Entre mulheres. Comício, 31 jul. 1952c. Disponível em: <http://docvirt.com/DocReader.net/DocReader.aspx?bib=AcervoRubemBraga>. Acesso em: 18 dez. 2018.

MESQUITA, Cláudia. De Copacabana à Boca do Mato. O Rio de Janeiro de Sérgio Porto e Stanislaw Ponte Preta. Rio de Janeiro: Casa Rui Barbosa, 2008.

MOSER, Benjamin. Clarice, uma biografia. São Paulo: Cosac Naify, 2011.

NUNES, Aparecida Maria. Clarice Lispector jornalista: páginas femininas e outras páginas. São Paulo: Senac, 2006.

NUNES, Aparecida Maria. Clarice Lispector na cabeceira - Jornalismo. Rio de Janeiro: Rocco, 2012. PINSKY, Carla Bassanezi. Mulheres nos anos dourados. São Paulo: Contexto, 2014. 